\title{
INVESTIGACION
}

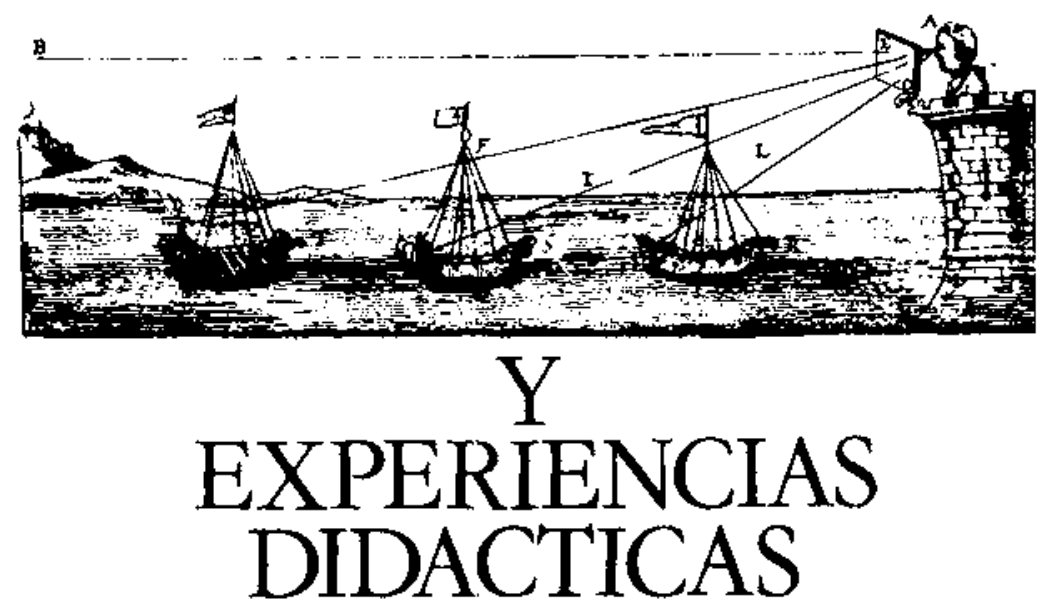

\section{STUDENTS' LEARNING DIFFICULTIES IN SCIENCE. CAUSES AND POSSIBLE REMEDIES}

KEMPA, R. F.

University of Keele, Staffordshire, UK.

\section{SUMMARY}

In this paper, a broad analysis is presented of the main types of learning difficulties encountered by students in science education and causes underlying them.

Teachers and educationists make frequent use of the terms 'learning problems' and 'learning difficulties', but no generally accepted definition exists of their precise meaning. Yet, it seems to me that without some clarification of these terms it is hardly possible to begin to identify such difficulties, let alone talk meaningfully about their nature and about how they can be overcome or remedied.
It is possible, of course, to appiy the term "learning difficulty' to any situation where a student fails to understand a relatively easy concept or notion that we wish him or her to acquire as the result of some instructional intervention. Such description of "learning difficulty' is of little practical value, though: it is too general and all-embracing and, in addition, does not even hint at the possible causes of such difficulties. Let me, there- 
fore, propose a somewhat narrower definition:

"A learning difficulty may be said to exist in any situation where a student fails to grasp a concept or idea as the result of one or more of the following factors:

i. The nature of the ideas/knowledge system already possessed by the student, or the inadequacy of such knowledge in relation to the concept to be acquired.

ii. The demand and complexity of a learning task in terms of information processing, compared with the student's information-handling capacity.

iii. Communication problems arising from language use, e.g., in relation to technical terms or to general terms with context-specific specialized meanings, or the complexity of sentence structure and syntax used by the teacher (compared with the student's own language capacity).

iv. A mismatch between instructional approaches used by the teacher and the student's preferred learning mode (learning style)."

No claim is made for this definition to be comprehensive, and there may well be other points that could and should be added to it. What the definition does attempt, however, is todraw attention to a range of causes of learning difficulties which can possibly be remedied through appropriate pedagogical interventions or curricular strategies.

It ought to be acknowledged at this stage that a student's failure to learn what we wish him or her to learn, cannot always be attributed to 'learning difficulties' in the sense of the above definition. Other reasons may also prevail and be responsible for students' failure to learn, e.g., lack of interest, an inadequacy of effort or a lack of attention. Practising teachers are well aware of the importance of these factors-indeed, they frequently invoke them in order to 'explain' lack of performance and low achievement on their students' part. Despite their obvious impact on students' learning, I view these factors as relating to what Gagne (1965) has described as "preconditions for learning", rather than to the leaming process itself. For this reason, I have excluded them from my list of causes of leaming difficulties.

The division of students' learning difficulties and their underlying causes into the above four areas is, to some extent, a matter of convenience and expediency. It reflects the fact that these categories correspond to fairly well-established areas of research. This is not to say that the areas should be viewed as relatively independent of one another. On the contrary, there are definite links between them.

Both the first and the second area indicated above may be said to relate to the learners' knowledge and memory structure, but each does so in a different way. Whereas the first is concerned with the nature of the knowledge held by learners in what, in terms of an informationprocessing model, is generally referred to as their 'longterm memory' (LTM), the second area focuses on stu- dents' 'short-term memory' (STM), sometimes also referred to as 'working memory'.

When considering inadequacies in working memory as a source of learning difficulties, the focus is not on the structure of ideas held by students in their memory, but on the capacity of students to hold and manipulate different pieces of information simultaneously. Considerable experimental evidence exists now to suggest that people differ with respect to the number of items of information on which they can operate in tasks requiring the transformation of information (learning tasks invariably require this). Therefore, any 'mismatch' between the complexity of a learning task (when seen in terms of the number of information items to be handled) and a student's information-handling capacity must be seen as a potential source of learning difficulties.

The third area suggested above covers a range of issues that may be summarized under the label "language and communication'(1). This is a widely researched area, particularly in relation to the exploration of students' understanding of technical and non-technical words in science. Prominent among these studies in the Englishspeaking context are those by Gardner (1972) in Australia and by Cassels and Johnstone (1977) in Britain. In the Spanish context, the work of Ilopis and colleagues at Valencia is noteworthy.

The particular aspects of 'language and communication' which cause or may contribute to learning difficulties in science, are too numerous to be listed here. Let me merely indicate that they extend beyond students' understanding of the meaning of words. Factors such as the complexity of teachers' speech and/or textual materials for use by students are probably no less important in this context, especially when one recognizes that 'complexity' is a muIti-faceted concept. Other languagerelated aspects of considerable interest in science education include the use of metaphors and the terms and analogies used in the description of abstract notions and concepts.

The fourth and final area embraced by the above definition of learning difficulties concerns the relationship between teaching style (as exemplified by the instructional approach adopted by a teacher or recommended for the implementation of a curriculum) and learning style (which may be thought of as representing a student's 'natural' or preferred mode of attending to a learning task). Frequent reference has been made in the literature to the desirability of matching teaching styles to students' learning. Research evidence in support of this notion is, however, rather scant.

Compared with the first three areas proposed above, the fourth is rather less well defined conceptually and must, hence, be more speculative in terms of its practical exploration. Notions such as teaching style and learning style are exceedingly complex. Except for some relatively coarse attempts, we still lack a good operational identification and characterization of teaching styles. (Eggleston and co-workers, in 1976, arrived at three broad 'types' of science teacher, each characterized by its own teaching style.) 
The task of conceptualizing and identifying genuine learning styles is no less difficult. Hofstein and Kempa (1985), following a suggestion by Adar (1969), made a limited attempt in this direction in relation to science learning. This was based on the premise that students' learning styles are reflected in their preferences for, or dislike of, particular instructional procedures. Recently, Kempa and Martin (1989) have explored this area empirically. (See also Kempa and Martín Díaz 1990 a, b.)

The four areas suggested here differ considerably in terms of the amount of attention that has been given to them by science education researchers. The first area, in particular, has been the subject of considerably more research than any of the other areas. Hence, our insight -as science educators and teachers-into the relationship between students' learning (and problem-soiving) difficulties and their long-term memory is now fairly well developed.

In relation to the other areas, our knowledge base is somewhat weaker. (This is especially true for the fourth area mentioned, which concerns the matching of teaching approaches and learning styles.) This means that the extent to which research findings in these areas are translatable into guidelines and suggestions for curricular actions is limited. Even if such guidelines are developed, they may have to be viewed with some caution, as far as their validity and generalizability are concerned. However, this does not make these areas less important than the first one. What it does mean is that in future increased attention needs to be given by science teachers and researchers to these areas also.

\section{EXPIORING THE IMPLICATIONS OF RE- SEARCH INTO LEARNING DIFFICULTIES -THE ROLE OF MODELS OF LEARNING/ TEACHING}

The major idea underlying the whole area of learning difficulties, at least in relation to the causal categories discussed in the preceding section, is that of 'mismatch'. By this I mean that learning difficulties do not exist in vacuo, but appear only in situations where teaching intentions and interventions are not adequately matched to the Icarner's intellectual capabilities or cognitive, functioning. The actual nature of the mismatch can, of course, vary considerably (as has already been explained in the previous section), but generally mismatch is attributable to some 'deficiency' in the learner's knowledge structure or his/her verbal repertoire, etc.

From a theoretical perspective, any attempt to remedy or reducc a learning difficulty must address itself to the negation of the underlying mismatch or deficiency, by means of appropriate interventions. In principle, such interventions can take two forms, viz.,

- the provision of supplementary instruction designed to fill knowledge gaps and/or widen the meanings tha: students associate with particular notions and concepts;

- the modification of instructional approaches either to avoid or by-pass the particular causes of a learning difficulty, or to provide the learner with experiences that enable him/her to resolve the difficulty.

It is probably not unreasonable to assume that a teacher or curriculum developer, in adopting a particular mode of intervention, does so in the expectation that it is 'appropriate' to a perceived learning difficulty, i.e., that it will remove or resolve the latter. The only exception here would occur if an amelioration strategy were chosen entirely on a trial-and-error basis. Ignoring this exception, we may claim that interventions chosen by teachers to overcome particular learning difficulties reflect their assumptions not only about the causes of the difficulties, but also about the methods suitable for resolving them. Such assumptions are essentially the result of 'model constructs' of learning and teaching, irrespective of whether these are held on an individual basis or whether they enjoy consensus status.

It follows from the foregoing that the conception of learning and teaching held by a teacher or a curriculum developer is likely to be a major determinant of the strategy chosen by him/her for the negation or reduction of learning difficulties. For this reason, some consideration has to be given to the role of models of teaching/ learning in developing strategies for remedying learning difficulties.

For a learning theory to be potentially useful as a basis for the choice of pedagogical interventions for overcoming learning difficulties, it has to fulfil two essential requirements:

i. It must incorporate characteristics that relate or address themselves to the causes of learning difficulties, and

ii. it must invoke or postulate some mechanism whereby knowledge change, etc., is brought about.

In relation to the first of these points, the observation has to be made that no single learning theory that is currently available, is capable of accounting adequately for the whole spectrum of causes of learning difficulties. Therefore, several learning theories have to be called upon if we are to deal with different types of learning difficulty. This is not a serious drawback, provided that the different theories complement, rather than contradict, one another.

The second requirement specified above should be largely self-explanatory. It is based on the recognition that nonmechanistic learning theories are usually 'descriptive' in nature and so have little value as foundations for making decisions about the choice of pedagogical interventions and strategies (cf. Kempa 1983).

Most of the theoretical positions that underlie, or are implicit in, researches into students' learning difficulties and/or attempts to remedy them may be associated with two major perspectives. These are the constructivist perspective of learning and the information-processing 
perspective, respectively. Following Osborne (1985), the distinction between these perspectives is best expressed in terms of their respective concerns:

"A central feature of the constructivist tradition concerns knowledge: the concepts, meanings, understandings... and intellectual skills stored by an individual in memory"... [whereas] "the information-processing tradition is morc concerned with the problem-solving capacity of the human mind and with the thinking processes that occur when problems are tackled."

This distinction is useful in that it points to the constructivist perspective as the model appropriate for the consideration of learning difficulties which arise from inadequacies in the learner's knowledge structure, i.e., his/her long-term memory. In contrast, the information-processing perspective has obvious relevance to learning problems which stem from difficulties in information-handling and transformation, which relate to the learner's working memory.

The language area (which forms the third of the four arcas identified in our definition) can also be linked to the constructivist model, provided that language is regarded as a means of learning, rather than just as a communication system. The former viewpoint has found increasing acceptance in recent years. To quote Solomon (1987):

"The construction of meaning through language... does more than extend and refine the vocabulary -it builds up the very picture of reality just as powerfully as does the sum of sensory perceptions and experiences."

Summarizing the discussion in this section so far, we may claim that the constructivist theory of learning and the information-processing model, between them, form a reasonable theoretical basis for the interpretation of the first three areas of learning difficulties identified in the preceding section. Moreover, it is possible to derive from these theoretical models a series of pedagogical principles for avoiding and/or remedying learning difficulties.

As has already been stated, in relation to the fourth area of learning difficulties (i.e., that concerned with the mismatch between learning styles and instructional styles) our theoretical understanding is less well developed. So is, in consequence, our ability to articulate pedagogical strategies whereby this type of mismatch can be avoided or reduced. The reason for this situation lies largely in the complexity of the learning/tcaching process. Although numerous researches have explored specific aspects of learning/teaching interactions, information derived from them is still too fragmented to allow us to make holistic pronouncements about the instructional process.

Nevertheless, some theoretical positions can be arrived at which, although far from comprehensive, may be used as a start to a closer matching of teaching and learning styles. Kempa and Martin's (1989, 1990a, 1990b) study of the relationship between students' motivational patterns (which manifest themselves in preferences for different learning modes) and instructional strategies in science education, forms an example of this.

\section{SOME EXAMPLES AND APPIICA'TIONS}

In the discussion so far, the emphasis has been on the clarification of the concept of 'learning difficulties in science' and on the establishment of some theoretical framework within which such learning difficulties can be understood, interpreted and possibly remedied. My intention now is to illustrate some of the aspects mentioned above by reference to some actual examples and research findings. Having so strongly focused on the role of long-term memory and working memory as key factors in causing learning difficulties, I propose to pay particular attention to these two aspects, to the exclusion of the others.

It may be helpful at this juncture to reflect briefly on the respective functions of the two memories in learning and/or problem-solving. Figure 1 helps to illustrate these in a schematic form. We may think of the long-term memory as a vast knowledge store from which information is drawn and to which information is added from time to time. The working memory in this representation may be likened to the central processing unit of a computer system: it is here where the information derived from the long-term memory and from outside is brought together in mental operations and transformations. 'l'he results of these processes must inevitably reflect (i) the nature of the information held in the learner's long-term memory and (ii) the capacity of his/her working memory - which obviously links to the points previously made.

Figure 1

Sclicmatic representation of information-processing model.

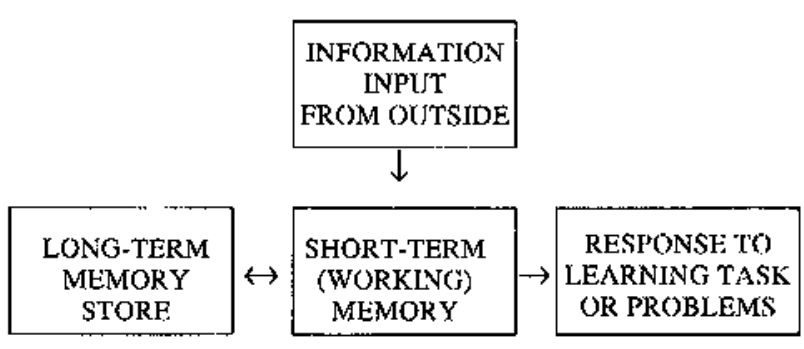

\section{Long-term memory structure and science learning}

The literature abounds with reports on the views and ideas on scientific phenomena, held by pupils and students before and after instruction. The last few years in particular have seen a proliferation of studies in this area. As a result, we have now available a good deal of information about many of the ideas and misconceptions held by pupils and students about scicntific phenomena and events [see, e.g., Driver and Erickson (1983) and Gilbert and Watts (1983)]. 
Let me give here just one example of findings about students' understanding of scientific phenomena, in order to explore the relationship between long-term memory structure and science learning. The example is taken from the Children's Learning in Science project (CLIS 1987), recently conducted in England. The project set out to identify in a systematic way the ideas held by secondary school students about a range of scientific themes and to explore ways of remedying any misconceptions.

One of the themes investigated concerned the relationship between the behaviour of gases and their particle nature. Students' understanding of this was examined by questions such as this:

"After many experiments, scientists now think that

- all things are made of small particles

- these particles move in all directions

- temperature affects the speed they move

- they exert forces on each other.

Use any of these ideas to explain the following: A football is pumped hard during the day when it is warrt. In the evening when the temperature falls, the football does not feel so hard."

To illustrate the range of notions held by students about this phenomenon, let me give a few of the actual answers received.

\section{Answer a:}

"When it is warm, the air particles in the football are moving around fast and are spread out. However, when the football becomes cooler, the air particles slow down and come nearer to each other, i.e., the air contracts. Therefore there is less pressure on the ball..."

\section{Answer b:}

"When the weather is warm, the particles inside the ball have expanded so that the ball will hold no more air... In the evening when the weather is not so hot, the particles shrink so they no longer fill the space in the ball..."

\section{Answer c:}

"When it is warm, the particles in the air (inside the ball) are moving all over and so make it hard... But in the evening, when the temperature drops, the particles stop moving about..."

These student's answers, which are typical of a wide range of answers received, reveal certain noteworthy characteristics. Answer $a$ is clearly acceptable in the scientific sense. It brings out the link between temperature and the speed at which the particles in the air move, which is the essential feature of a correct interpretation of the phenomenon.

Answers $b$ and $c$, in contrast to answer $a$, express distinct misconceptions. The first of these, appearing in $b$, is that the particles themselves undergo a change in size as the temperature of the air changes ('the particles expand', 'the particles shrink'). The second, shown in $c$, stipulates that the particles are not necessarily in continuous motion (they 'stop' on cooling).

Misconceptions like the foregoing (and there are many others in evidence in other areas of science) are readily attributable to 'inadequacies' in students' long-term memory structure, as already hinted at earlier. In the case of the first misconception, the student evidently made an incorrect connection between the macroscopic properties of a bulk of matter and the microscopic particles of which matter is composed. (Another example of this, frequently encountered in science teaching, is students' assumption that the atorns of a metal such as copper or gold, have the same colour as the metal itseif.)

The second misconception likewise can be interpreted in terms of inappropriate links between knowledge items in the learner's memory structure. The two knowledge items involved here are that

a. the reduction in temperature causes a slowdown of the particles, and

b. a slowdown in the speed of an object results ultimately in the loss of any movement.

The latter is, of course, a common everyday experience associated with, for example, the braking action of a car.

The kinds of link between knowledge elements in a student's memory structure that we are stipulating here, must, in the first instance, be regarded as hypothetical constructs. The questions arise whether such memory structures may actually be unfolded and, if so, whether they give any clues about students' learning difficulties.

Some of our own work at the University of Keele has sought to answer these questions. Using a technique called word-association testing, we have explored students' knowledge structures in relation to selected areas of chemistry and presented these in the form of 'cognitive maps'. Comparing the cognitive maps of students of different ability in the areas covered by the maps has enabled us to shed some light on the influence of students' knowledge structure on their learning and problem-solving behaviour.

In their simplest form, cognitive maps show graphically the links and associations among different related concepts and notions, as they exist in a student's mind. It is not necessary for the nature of the links to be made explicit, as long as one can reasonably interpret the cognitive maps. Let me illustrate this by two examples which relate to the concept areas 'acid' and 'electroly. sis', respectively. In each case, we contrast the cognitive maps of students who, in problem-solving tasks relating to the two concept areas, had been successful and unsuccessful, respectively. The cognitive maps representations are given in figures 2 and 3.

Considering figure 2 first, it is seen that the main difference between the two cognitive maps lies in the absence 
Figura 2

"Average" cognitive maps for the concept ACI1), for (a) good and (b) poor problem-solvers.

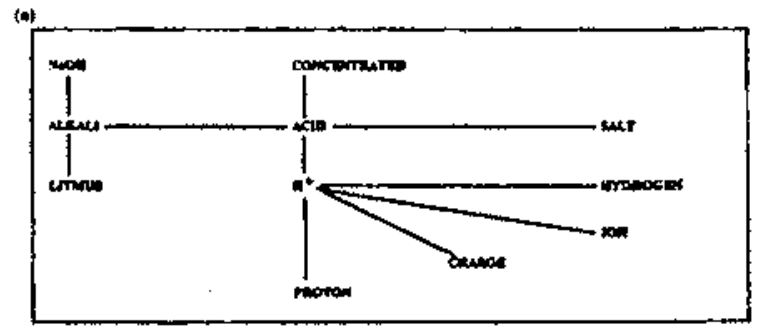

at

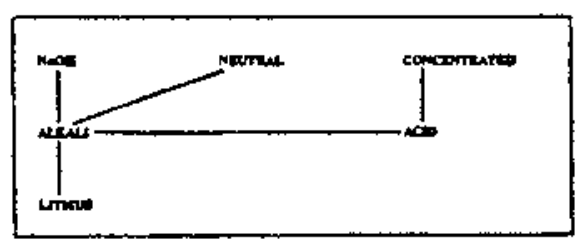

from that for the 'poor' problem-solvers of a set of concepts/notions which may be said to be 'abstract' in nature. In all other details, the maps appear identical.

What we may conclude from these maps, is that students who, in relation to matters concerning 'acids', turn out to be poor problem-solvers, lack particular knowledgeelements that are usually regarded as important: in this case, the 'absent' concepts are the proton, or hydrogen ion (Kempa and Nicholls 1983).

Figure 3 which is based on experimental work by Slimming (1984), is significantly more complex in that it deals with a broader subject area (electrolysis). Comparing the two representations, it is noted that the knowledge elements found in the two maps are approximately the same. However, the representations differ substantially in the nature and extent of the links between concepts and knowledge elements. Figure 3(a) shows links and associations which, to the experienced science/chemistry teacher, appear logical and justifiable. Figure 3(b), in contrast, contains fewer connections (the cognitive map is more fragmented) and quite a few of these are illogical, from a scientific point of view.

We should, of course, not be surprised to find that the cognitive structures, as they exist in students' long-term memories, have considerable influence on the way in which students can grasp or make sense of new information and ideas. Thus, a direct connection emerges between cognitive structure (long-term memory structure) and learning difficulties.

Our own findings and those of other researchers lead to the conclusion that long-term memory related learning difficulties are usually attributable to one or more of the following factors:

- The absence of knowledge elements from a student's memory structure.
Figura 3

Cognitive maps for the concept Eletrolysis. The top map applies to a good problem-solver, whilst the bottom map is that of a poor problem-soiver.
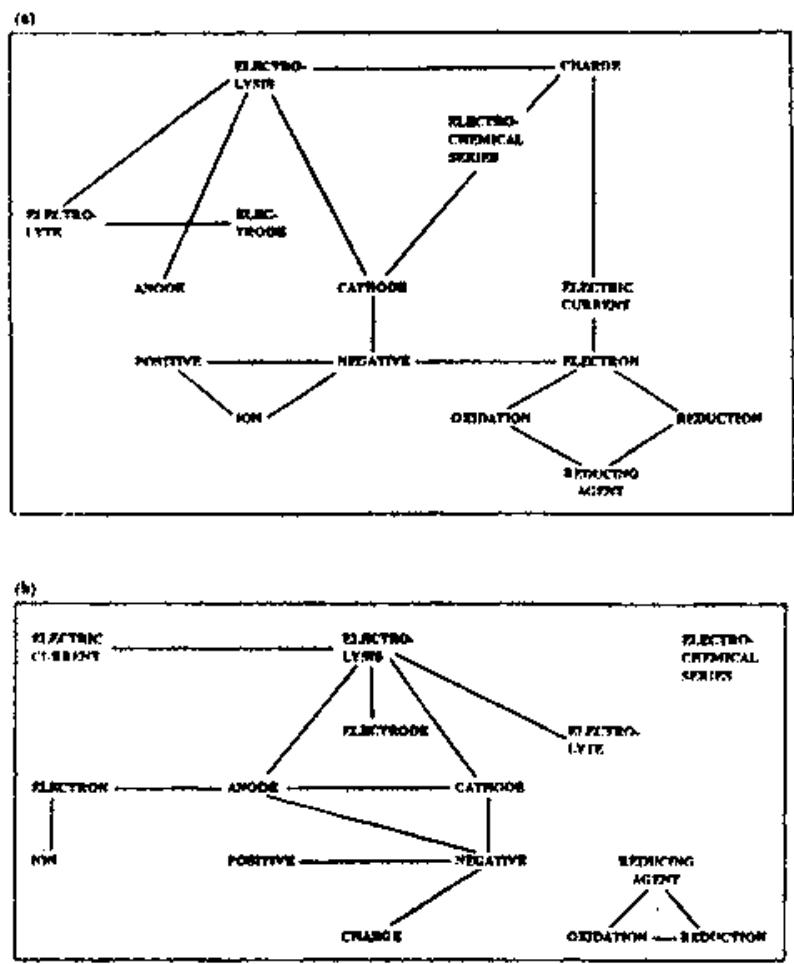

- The existence, in the student's memory structure, of wrong or inappropriate links and relationships between knowledge elements.

- The absence of essential links between knowledge elements in the student's memory structure.

- The presence of false or irrelevant knowledge slements in the student's memory structure.

Each of these 'deficiencies' is illustrated by the cognitive maps presented here. These maps deal with relative. ly small areas of subject matter. For more complex fields, more extensive maps could probably be constructed, but their increasing complexity would make them more difficuit to present graphically and to interpret.

I have not so far referred to learning problems that arise from pupils and students holding scientific notions that are in conflict with those accepted by scientists. These are often referred to in the literature as alternative frame. works, children's science or commonsense science, etc. Essentially, these are covered by the present discussion also: alternative frameworks may be viewed as the result of students holding knowledge structures, that are different from those of the scientist.

The types of deficiency in (long-term) memory structure provide at least a partial explanation of the learning difficulties that we frequently detect our students to 
have. The recognition and diagnosis of these deficiencies also provides a natural starting point for the design of teaching strategies by means of which students' learning difficulties can be reduced or overcome.

One such teaching strategy is that developed and used by the 'Children's Learning in Science project' (CLIS) mentioned earlier (Needham and Hill 1987). It is based on the constructivist model of learning and incorporates features previously suggested by authors such as Nussbaum and Novick (1982) and Novak and Gowin (1985). Table 1 outlines the main characteristics of this teaching approach. As can be seen, great emphasis is placed on

i. the provision of opportunity for pupils to become aware of the ideas which they hold prior to being taught (Elicitation of Ideas);

ii. the modification, extension or replacement of such ideas, if found inadequate, by new ones (Restructuring of Ideas).

The teaching sequence implicit in table 1 has been fairly successfully applied by the CLIS team in several areas of science teaching.

Table I

Teaching sequence proposed and used by the CLIS project (ct. Needham and Hill 1987).

\begin{tabular}{|c|c|c|}
\hline Pthast & PLRPOSE & METHNOS \\
\hline L ORIENTATION & 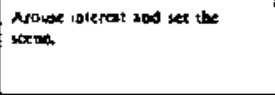 & 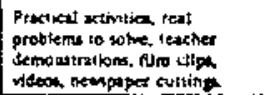 \\
\hline $\begin{array}{l}\text { I. ELtCriation SP } \\
\text { IDEAS }\end{array}$ & 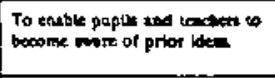 & 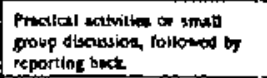 \\
\hline $\begin{array}{l}\text { I1. RESTRUCTURINU } \\
\text { OF IDENS }\end{array}$ & 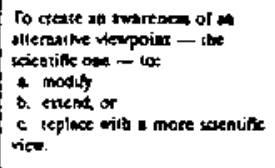 & \\
\hline $\begin{array}{l}\text { 1. Goriaksition ano } \\
\text { tasang }\end{array}$ & 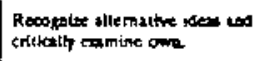 & $\begin{array}{l}\text { Smafl goup disceussige and } \\
\text { reporting back }\end{array}$ \\
\hline $\begin{array}{l}2 \text { Esponure to confitat } \\
\text { siluitots }\end{array}$ & 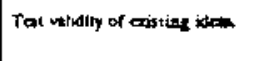 & 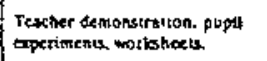 \\
\hline $\begin{array}{l}\text { 3. Construction of new } \\
\text { item }\end{array}$ & $\begin{array}{l}\text { Modily. entend or replase } \\
\text { costing ivear }\end{array}$ & $\begin{array}{l}\text { Dlsousion, reading texker } \\
\text { inpul }\end{array}$ \\
\hline a Enluatko & 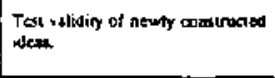 & $\begin{array}{l}\text { Pracical prork, projart mork } \\
\text { crperimentalion, teachez } \\
\text { demonstration. }\end{array}$ \\
\hline $\begin{array}{l}\text { IY. APPLICATION OF } \\
\text { IDEAS }\end{array}$ & 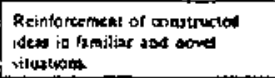 & $\begin{array}{l}\text { Personal writing prostical } \\
\text { acimay, problen solvteg profect } \\
\text { wofe }\end{array}$ \\
\hline V. REVIEW & 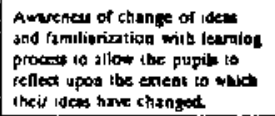 & 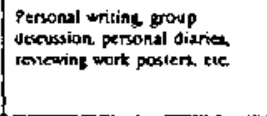 \\
\hline
\end{tabular}

\section{Working memory capacity and learning difficulties}

In the introductory section of this paper, attention was drawn to the central role played in learning processes by the short-term or working memory (cf. figure 1). We may interpret 'working memory' as that part of a person's intellectual functioning in which information from external events and from one's long-lcrm memory is brought together and processed.

It is well established through psychological research that the capacity of our working memory is rather limited. For example, according to Miller's studies in the 1950 s (Miller 1956), most people can hold only about $7 \pm 2$ information units in their short-term (working) memory. Broadbent (1975) even suggests that Miller's figure is too high; but more important in the present context than a debate of whether the average figure is 7 or less are the following findings from educational research:

- The working memory capacity is different from person to person.

- For a particular person, the working memory capacity appears fairly constant.

- The number of information units with which a person can work simultaneously, tends to fall within the range $X=4$ to $X=7$.

These findings are largely due to the Canadian psychologist Pascual-Leone (1972).

The immediate consequence of the foregoing points must be that, if a learning task makes excessive demands on a student's working memory, learning difficultics will ensue. We may postulate the following:

If the number of information units required for a learning (or problem-solving) task is in excess of the learner's working memory capacity, the task cannot be solved.

Johnstone and co-workers, in a scries of recent investigations, have provided considerable evidence in support of this postulate. In one of their investigations (Johnstone and El-Banna 1986), they attempted to establish a relation between

i. the working memory capacity of students,

ii. the theoretical complexity of a range of chemical problerns, measured in terms of the information units required for their solution, and

iii. the proportion of students who were successful in solving these problems.

The resuit of the study which was carried out on 471 upper secondary and university students, are summarized in figure 4. It is seen that the success rate in the problem-solving situations strongly decreases as soon as the number of the information units involved in the problems exceeds the working memory capacity of the students. 
Figure 4

Resulls ohtained by iohnstore and fil-Bumbr (1986).

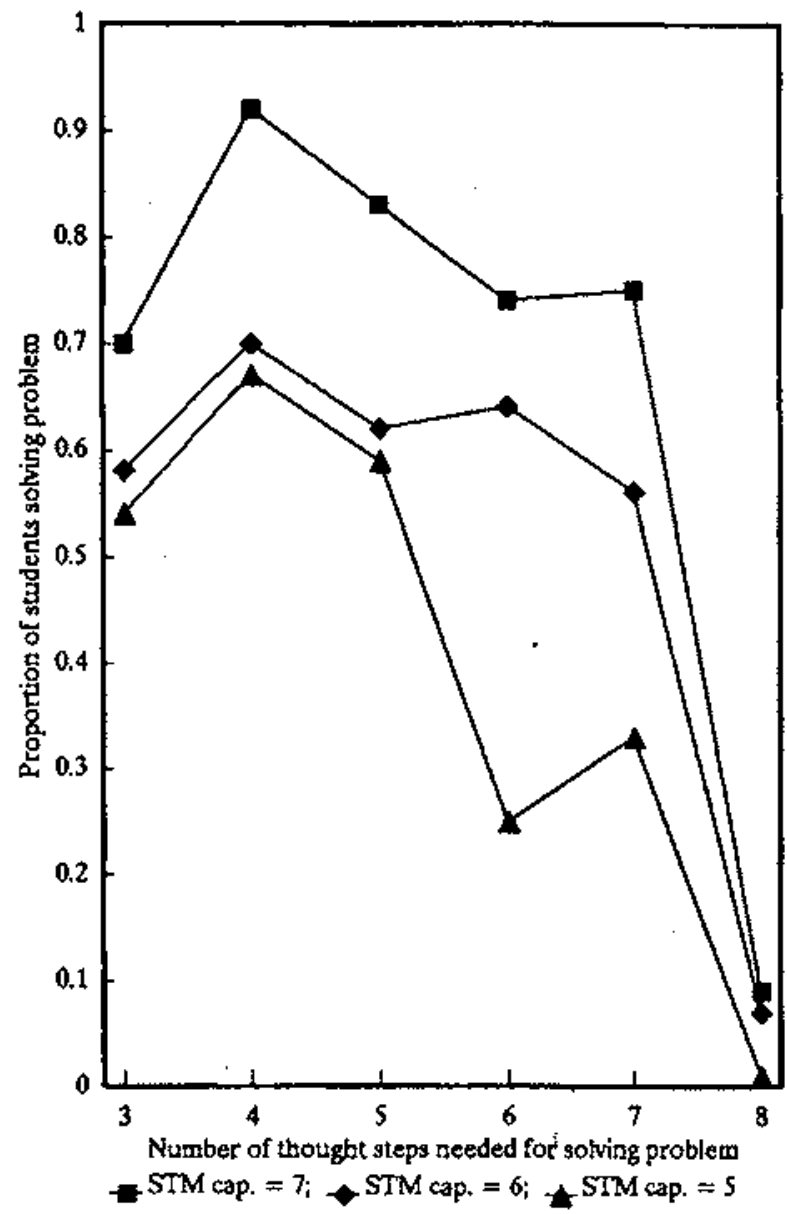

What is true for problem-solving tasks must, of course, be equally true for learning tasks. Hence, it is evident that learning difficulties are attributable not only to deficiencies in students' long-term memory structure, but also to limitations in their short-term or working memory capacity.

White (1988) gives a simple, but instructive example of this with reference to the statement "Concentrated sulphuric acid is a powerful dehydrating agent". He suggests that a relatively inexperienced student would probably perceive this statement as comprising a large number of information elements, e.g.,

(Concentrated) (sulphuric) (acid) (is a) (powerful) (de) (hydrating) (agent).

An experienced teacher, by comparison, may perceive the same statement in a far less fragmented way, e.g.,

\section{(Concentrated sulphuric acid) (is a) (powerful) (dehydrating agent).}

Thus, what to the inexperienced learner appears as a conglomerate of seven or eight separate information units, is seen by the expert as a set of four such units.
The process of bringing together elements of information into groups or parcels is generally referred to as 'chunking'. It is through the process of chunking that we reduce for ourselves the complexity of the information that reaches us. As White (1988) remarks:

"Size and therefore number of chunks perceived in a situation is one of the big differences between the knowledgeable person (expert, teacher, adult) and the ignorant (beginner, student, child). Almost paradoxically, an expert inhabits a simpler world than a beginner because the expert breaks it into a smaller number of meaningful units."

The last point in White's statement is insufficiently appreciated by us in relation to our teaching and our students' learning. We tend not to be aware of the fact that our students are incapable of dividing the information with which we confront them into the kinds of chunks that we recognize in it. The result is an overload of their short-term (working) memory and a consequential failure to learn the full message.

This situation does not simply apply to verbal information, but is equally possible in the case of graphical or diagrammatic information. White (1988) has recently illustrated this aptly in his book entitled Learning Science.

The key to helping students overcome learning difficulties arising from the limitations in their working memory lies in helping them to see information in larger and, hence, fewer units (or 'chunks'). I want to propose three main methods for achieving this:

a. Careful and purposeful structuring of information given to students, including the learning and problemsolving tasks set, into information units that are clearly recognizable by them. (This may be referred to as a 'prechunking' operation.)

b. Avoidance in the design of texts, laboratory instructions, examination questions, etc., of superfluous, unnecessary information. (Such information contributes to 'memory-overload' and, hence, distracts from the essential content of the communication.)

c. Deliberate training of students in 'chunking' strategies, through the systematic analysis of information presented to them and ways in which it can be organized and arranged. In this way, they should learn to perform beyond the limits of their own short-term memory capacity.

There are numerous ways and opportunities in all bran. ches of science teaching where these methods can be effectively employed, for the benefit of our students.

\section{CONCLUSION}

In this paper, a broad analysis has been presented of the main types of learning difficulty encountered by stu- 
dents in science education and the causes underlying them. The general premise was adopted that, by and large, such learning difficulties are the result of deficiencies or of mismatch. The deficiencies may occur in the knowledge structure held by students in their long-term memory, or in their information-handling capability which is due to limitations in short-term memory capacity. Mismatch may occur when teaching strategies used by teachers are in conflict with students' natural learning styles or their preferences for certain instructional procedures.

The detailed discussion has centred on the nature of memory-related learning difficulties. In this, reference was made to the use of cognitive mapping as a means of

\section{NOTE}

(1) Since "language and communication" issues in science education ultimately concern the meaning acquired by siudents through the use of words and sentences, it can be argued that such meanings are dependent on students' knowledge structure. On this basis, "Ianguage and communication" would

\section{REFERENCES}

ADAR, L., 1969. A Theoretical Framework for the Study of Motivation in Education. The Hebrew University, Jerusalem (in Hebrew).

BROADBENT, D.E., 1975. The magic number seven after fifteen years, in Kennedy, A. and Wilkes, A. (eds.), Studiss in Longterm Memory. (Wiley: London).

CASSELS, J.T.R. and YOHNSTONE, A.IX, 1977. Language in Chemistry. In Research for the Classroom and Beyond Report of a Symposium. The Chemical Society (Now: Royal Society of Chemistry), London.

CI.IS (Children's Learning in Science Project), 1987. CLIS in the Classroom - Approaches to Teaching. Centre for St11dies in Science and Mathematics Education, University of Leeds, UK.

DRIVER, R. and ERICKSON, G., 1983. Theories-in-Action: some theoretical and empirical issues in the study of students; conceptual frameworks in science, Studies in Science Education, Vol. 10, pp. 37-60.

EGGLESTON, J.F., GALTON, M.J. and JONES, M.E. 1976. Processes and Products of Science Teaching. (Macmillan Eiducation: London).

GAGNÉ, R.M., 1965. The Conditions of Learning. (Holt, Rinehart and Winston: New York).

GARDNER, P., 1972. Words in Science. ASTEP (Austratian Science Teacher Education Project), Monash University, Clayton, Australia,

HOFSTEIN, A. and KEMPA, R.F., 1985. Motivating strategies in science education: attempt at an analysis, European Journal of Science Education, Vol. 7, pp. 221-229.

JOHNSTONE, A.H. and EL-BANNA, H., 1986. Capacities, demands and processes -a predictive model for science education. Education in Chemistry, Vol. 23, pp. 80-84. unfolding deficiencies and peculiarities in students' knowledge structure (long-term memory effects), as a starting point to remedying them. Similarly, attention was drawn to limitation in students' short-term memory capacity as a cause of failure in learning and problemsolving tasks. Suggestions were also outlined about how these memory-related learning difficulties can be reduced or avoided by appropriate pedagogical actions.

It is important for science teachers and educators to recognize and respond to these various causes of students' learning difficulties. Doing this will not only reduce these difficulties, but also make our teaching more effective. I hope that the ideas presented here provide an appropriate stimulus in this direction.

logically form part of the "long-term memory" area and, hence, would come within the purview of the information-processing model adopted above. However, there is some merit in according it a separate position, because of its general importance.

KEMPA, R.F., 1983. Learning Theories and the Teaching of Science: Implications for Science Teacher Training. In Tamir, P., Hofstein, A and Ben-Peretz., M., Preservice and Inservice Training of Science Teachers. (Balaban International Science Services: Philadelphia, USA).

KEMPA, R.F. and MARTÍN, M.J., 1989. Modelos Motivacionales y Preferencias de los Alumnos por diferentes Métodos de Enseñanza de las Ciencias, Enseñanza de las Ciencias, número extra (IYI Congreso), Tomo 2, pp. 37-40.

KEMPA, R.F, and MARTÍN DÍAZ, M., 1990a. Motivational traits and preferences for different instructional modes in science. Part 1: Students' motivational traits, International Journal of Science Education, Vol. 12, pp. 195-203.

KEMPA, R.F. and MARTÍN DÍA7, M., 1990b. Students' motivational traits and preferences for different instructional modes in science education. Part 2, International Journal of Science Education, Vol. 12, pp. 205-216.

KEMPA, R.F. and NICHOLLS, C., 1983. Problem-solving ability and cognitive structure -an exploratory investigation, European Journal of Science Education, Vol. 5, pp. 171-184.

NEEDHAM, R. and HILL, P., 1987. Teaching strategies for developing understanding in science. Centre for Studies in Science and Mathematics Fducation, University of Leeds, UK.

NUSSBALM, J. and NOVICK, S., 1982. Altemative Frameworks, Conceptual Conflict and Accommodation: Towards a Principled Teaching Strategy. Instructional Science, Vol. 11, pp. 183-200.

NOVAK, J.D. and GOWIN, D., 1985. Learning How to Learn. (Cambridge University Press: Cambridge, UK). 
MILLER, G.A., 1956. The magical number seven plus or minus two: Some limits on our capacity for processing information. Psychological Review, Vol.63, pp. 81-97.

OSBORNE, R, 1985. Theories of Learning. In Osborne, R. and Gilbert, J. (eds.), Some Issues of Theory in Science Education. (University of New Zealand: Waikato).

PASCUAI.LFONE, J., 1972. A Neo-Piagetian interpretation of conservation and the problem of horizontal decalages. Paper presented at the Canadian Psychological Association Mecting, Montreal, Canada.
SLIMMING, D., 1984. Problem-solving in the context of the GCE Ordinary Level Chemistry Examination. PhD thesis, University of Kecle, UK.

SOLOMON, J., 1987. The Soctal Construction of Children's Scientific Knowledge. Studies in Science Education, Vol. 14, pp. 63-82.

WHITE, R., 1988. Learning Science. (Basil Blackwell; Oxford, UK).

\section{RESUMEN}

Este artículo presenta un amplio análisis de los principales tipos de dificultad en el aprendizaje de las ciencias y de las causas que subyacen.

El trabajo comienza con un intento de clarificación de la expresión «dificultades de aprendizaje» a la luz de las recientes investigaciones en didáctica de las ciencias. Se señalan aś́, sin ánimo exhaustivo, cuatro causas fundamenitales de dificultad:

- La naturaleza del sistema de ideas/conocimientos que el estudiantes ya posee

- La complejidad de la tarea de aprendizaje, en términos de procesamiento de información, comparada con la capacidad del estudiante para manejar elementos de información

- Los problemas de comunicación derivados del uso del lenguaje

- El desajuste entre el modelo de enseñanza utilizado por el profesor y el estilo de aprendizaje preferido por el estudiante.

Tras describir con algún detenimiento dichos factores, el segundo apartado se centra en el papel de los modelos de enseñanza/aprendizaje, poniendo de relieve que la mayoría de las investigaciones realizadas en torno a las dificultades de aprendizaje de las ciencias se enmarcan en el modelo constructivista y en el de procesamiento de información.

En el último apartado se describen, a título de ejemplo, algunas dificultades asociadas, respectivamente, al sistema de ideas que el alumno ya posee y a su capacidad para manejar información, desarrollando propuestas para su detección y tratamiento. 